\begin{tabular}{|l|l|}
\hline Postprint Version & 1.0 \\
\hline Journal website & $\underline{\text { http://www.ingentaconnect.com/content/bpl/spol/2003/00000037/00000006/art }}$ \\
\hline Pubmed link & $\underline{00004}$ \\
\hline DOI & $10.1111 / 1467-9515.00360$ \\
\hline
\end{tabular}

\title{
Organizational Restructuring in European Health Systems: The Role of Primary Care
}

\author{
ANA Rico, RiCHARD B. SALTMAN AND WIENKE G. W. BOERMA \\ Ana Rico, European Observatory on Health Care Systems, Madrid Hub, Ministry of Health, Paseo del \\ Prado 18-20, 28071 Madrid, Spain. E-mail: arico@msc.es
}

\begin{abstract}
:
The main goal of this paper is to review the strategies developed across European health care systems during the 1990s to improve coordination among health care providers. A second goal is to provide some analytical insights in two fields. On the one hand, we attempt to clarify the relationships between pro-coordination strategies and organizational change in health care. Our main conclusion is that the specific features of health care impede the operation of either market or hierarchical coordination mechanisms. These can, however, be selectively successful if applied as levers to promote the role and impact of the pro-cooperative coordination strategies which are ultimately required to foster adequate inter-professional and inter-organizational coordination. On the other hand, we try to cast some light on the ongoing debate on convergence versus path dependency within the broader field of welfare state reform. Evidence on pro-coordination reforms in health care apparently supports some insights from previous work on the centrality of the socio-political structure to account for varying patterns of selective path dependency across countries. In particular, the informal power resources of specialist physicians vis-àvis primary care professionals and the state are critical to explain the different rhythm and fate of pro-coordination reforms across Europe. Against received wisdom, the evidence examined suggests that selective path dependency might apparently be compatible with a general trend towards convergence understood as hybridization.
\end{abstract}

\section{INTRODUCTION}

This paper analyses the dynamics of organizational change in European health care systems. Our main goal is to review the strategies developed within Western European systems during the 1990s to improve coordination among health care providers. Inter-organizational coordination has long ranked high on the health care agenda. In practice, efforts in that direction have been rare, and often perceived as falling short of achieving the desired objectives. During the 1990s, in contrast, a series of procoordination strategies have been launched in European health care systems.

We pay special attention to primary care (PC), based on the perceived strategic importance of steering-system coordination from this level, partly confirmed by the now robust evidence on the 
moderating effect that a strong PC sector has on health spending (Gerdtham and J önsson 2000). Two important moves have been expanding task profiles of PC at the expense of other providers, and increasing the power of PC to steer other levels of care. Both changes imply a shift in broader systemcoordination mechanisms. They have apparently been effected in parallel with a shift in resources and control mechanisms, and within a context of mounting societal and financial pressures on health care systems.

The evidence on organizational restructuring in European health care is used to address three theoretical questions. First, is there convergence in pro-coordination policies through Europe? How do the mechanisms adopted differ across European countries? Second, what is the impact of different types of pro-coordination policies? Is there a model of best practice which could work across different health care systems? Third, which are the drivers and barriers of recent pro-coordination reforms in health care? To what extent do they differ across European countries?

In section 2 we sketch the analytical framework. Section 3 describes recent pro-coordination strategies in health care, and reviews the available evidence on their impact, based on a comprehensive review of literature since 1995. Section 4 discusses the analytical issues introduced in section 2 in the light of the evidence described in section 3.

\section{UNDERSTANDING PRO-COOPERATIVE REFORMS IN EUROPE}

\subsection{Network coordination as inter-professional cooperation}

We depart from a simplified view of organizations as pools of (financial, informational, human and technological) resources steered through a set of governance mechanisms. A further analytical simplification, widely used in economics as in political science (e.g. Ring and Van de Ven 1992; Scharpf 1993), consists of the three generic types of organizational governance: markets, hierarchies and networks. Most organizations combine elements of each. These three ideal-type models differ in the way they address the two main governance functions: coordination, and control (or motivation). The term coordination has traditionally been used to designate how the division of labour between different organizational units is re-integrated to achieve specific objectives. In modern organizational theory, its meaning is extended to include also the basic governance function of allocating tasks and decision-making powers among organizational units prior to re-integrating them. A necessary requirement for all coordination systems to operate adequately is that the involved actors comply with their expected courses of action. Compliance might derive from combinations of different control mechanisms: financial compensation, hierarchical power and social control by peers. More generally, all control mechanisms are based upon the allocation of costs, benefits, accountabilities and risks across organizational units and actors

Decentralized contracts and financial compensation have a critical role in markets; while hierarchies tend to rely on centralized directions, plans and power. Some particularly meaningful constraints on effective market and hierarchical coordination in the health care field are generalized uncertainty and asymmetric information problems. In addition, for market and hierarchical coordination mechanisms to be efficient, the interdependencies among different organizational units should be minimal. That is, units should be able to decide independently from each other most of the time. Otherwise the corresponding generalized externalities will hinder market coordination; or, alternatively, each unit hierarchical coordinator will have incomplete information and power to steer the required cross-unit interactions.

Networks can represent an efficient solution to those coordination barriers. Professions do indeed show some of the classic traits required for cooperative coordination mechanisms to work effectively, such as common socialization processes (training), high salience of reputation and shared value systems (deontology). However, the weakness of spontaneous professional networks prior to the 1990 reforms suggests that most likely they were not self-sustainable, and therefore depended on other supporting conditions which were not in place. A critical fact here is that until very recently, local selfcoordination among professionals has largely operated as an informal scheme, with formal coordination powers and budgets being attributed to state authorities or insurers (Goddard et al. 2000; Hughes Tuohy 1999; Goddard and Mannion 1998; Sheaff 1999; Mannion and Smith 1997). Other coordination barriers specific of networks are as follows. 
Hierarchies and markets mainly rely on unilateral decisions. In contrast, network coordination requires direct cooperation, based on group shared financial risks and decision-making. As a result, networks are costly in terms of decision costs and blockages (Scharpf 1988); and vulnerable to freeriding (Ring and Van de Ven 1992). Actors with better reputations (e.g. hospital vs. PC doctors) and organized interests (e.g. specialist-dominated physician organizations) will enjoy more power, which might not always lead to efficient coordination solutions. Because of the importance of trust, it is difficult to include new actors without an established reputation (e.g. nurses or managers). Finally, self-management makes actors focus on the most salient perceived interdependencies (clinical care), leaving other important strategic issues (e.g. cost, public health) uncoordinated (Scharpf 1993).

\subsection{Convergence as hybridization: testing selective path dependence}

Understanding organizational change requires not only examination of the organizational systems managing service provision, but also of the dynamics of policy change. The goal of the present paper is to test whether the theoretical model and hypotheses derived from a previous in-depth case study (Rico and Costa 2004) help explain the rates at which different types of European health care systems converge. We depart from a simplified view of the policy process as the dynamic interactions of a number of collective actors (or political organizations) subject to a set of formal rules of the game (formal political institutions). Contrary to other approaches, we concede a critical causal role to the socio-political structure (SPS) vis-à-vis institutions as a determinant of policy change.

Several clarifications are required here. We define institutions in more restricted terms than other research approaches, as the external rules of the game imposed by the state upon other collective actors. Regulation and legislation are therefore considered as almost synonymous with institutions. We understand organizations both as collective actors (capable of independent action) and ruled arenas (a set of internal "rules of the game"). To simplify terminology, we use the term organizational governance mechanisms to refer to the internal rules of the game operating within organizations. These are partly derived from, but not identical to, the external regulation prescribed by public policies. Policies in turn can be aimed at (1) modifying the rules of the game (institutional framework), or (2) allocating and redistributing (financial, knowledge and other) resources among collective actors. Institutional change (1) requires policy change of type (2) to be implemented (to achieve a subsequent transformation of organizational governance mechanisms).

We define the SPS in health care, following Hughes Tuohy (1999), as the distribution of informal political power (IPP) among three collective actors: state authorities, private entrepreneurs (insurers and others), and professionals. There are also three main sources of IPP: ownership and financial resources; knowledge and information resources; and social or political support (i.e. collective action resources). Citizens play a critical role in the latter. summarizes the main relationships between variables. Collective actors endowed with IPP can (a) exert informal pressures upon the political process (e.g. lobbying by private entrepreneurs and professional associations); and also (b) exercise formal influence mediated by the institutional framework (as in neo-corporatist schemes involving joint decision-making among professionals, insurers and the state). Institutions matter precisely because they translate socio-political actors' IPP into formal political power (FPP).

\section{[FIGURE 1]}

The SPS can be expected to evolve partly independently of the political system, driven by broader societal changes (such as an expansion of private health care following economic growth). Therefore, as time passes, the correspondence between formal institutions and IPP weakens, and resisting informal pressures for change will be increasingly difficult to resist for actors with FPP. As a result, policy shifts may result (c). There are two main feedback effects. Changed policy (d) prompts institutional change, and (e) modifies the SPS via resource shifts induced by public authorities. Policyinduced changes in the SPS in turn point to the centrality of the political process as an endogenous determinant of social change.

Based on Bouget (see below, this issue), there are three main positions within the debate on policy convergence: (1) all countries converge towards best practice; (2) clubs of countries converge towards shared policy solutions; and (3) each country endogenously develops its own policy changes through 
national trial and error processes. Position (1) argues that policy change is the result of broad external societal pressures which affect all countries. Positions (2) and (3) mainly focus on the role of institutional legacies in each country or group of similar countries as the main determinants of the type of policy change which can be effected.

The implications of our explanatory model for the debate on convergence are as follows. First, the success of societal pressures in bringing about policy convergence is likely to depend on the extent to which the new institutions threaten national IPP structures. Countries with initially compatible SPS will more rapidly and thoroughly adopt international best practice models. Elsewhere, unless parallel shifts in IPP resources are effected via redistributive policies, perceived threats will provoke opposition from socio-political actors; and therefore reduce the likelihood or scope of institutional change. Second, the latter will advance by the lines of least resistance in each country, thereby generating a progressive institutional and organizational hybridization. Accordingly, different patterns of selective $\mathrm{PD}$ are to be expected across groups of countries, rather than generalized convergence or PD. Third, our model opens the possibility that positions (1), (2) and (3) above, rather than alternative explanations, represent complementary phases of a longer-term convergence process understood as progressive hybridization.

\section{REDISTRIBUTING POWERS AND FUNCTIONS ACROSS THE INTERFACE: PRO- COORDINATION REFORMS IN EUROPEAN PRIMARY CARE}

Given our emphasis on system coordination, we classify PC reforms in three categories: (1) reforms that increase the power of PC (as purchaser or coordinator) over other care levels; (2) reforms directed at broadening the service portfolio of PC (as provider), often at the expense of other care levels; (3) concurrent changes in PC organizational resources and control systems. Strategies (1) and (2) imply a change in broader system coordination mechanisms, and therefore constitute our main focus of empirical analysis in this section. We conceptualize reforms included within strategy (3) as organizational requisites for the success of pro-coordination reforms, and discuss them in section 4 below.

\subsection{Increasing the coordination power of PC over other care levels}

Market mechanisms: delegating coordination power to PC purchasers Delegation of purchasing power to gate-keeping GPs constitutes an ambitious attempt to strengthen the role of the PC sector in system coordination through market-like mechanisms. The United Kingdom has successfully implemented different schemes and pilots in this direction since 1991. In particular, standard fundholding, by which individual GPs were entitled to purchase about 40 per cent of the specialist care, was extended to 40 per cent of the PC providers between 1991 and 1996 (1,500 PC groups), with more than 50 per cent of the population covered by the scheme (Bloor et al. 2000). Interestingly, in other NHS-type countries, purchasing powers were delegated to local authorities or agencies rather than GPs. Similar, but much smaller-scale, reforms, also targeting GPs (e.g. an experiment in Berlin, and a pilot experiment in Leningrad), have been piloted with little success in other Bismarck and Semashko countries (see section 4.2 for a description of different European health care systems).

Systematic reviews of the available evidence point to relatively encouraging results: giving GPs purchasing powers seems to have a positive impact on efficiency (by lower prices for hospital services and shorter waiting periods); on responsiveness to patient needs and preferences; and, after initial opposition, also on the professional status and satisfaction of fundholding GPs. Evidence about the impact of the scheme on equality and quality of care remains inconclusive (Mays et al. 2000; Bloor et al. 2000; Goodwin 1998; Whynes et al. 1999).

Cooperative arrangements across the interface. There is also evidence that the best-performing fundholding GPs spontaneously developed cooperative, network-like arrangements. Based on those bottom-up experiments, the British government launched two subsequent large-scale waves of procooperative, network-like reforms from 1996 onwards. In 1996-7, some 83 Total Purchasing Pilots (TPPs) involved a complete delegation of the purchasing function to GP group practices (Baxter et al. 
2000). In April 1999, some 481 PC Groups were created which involved compulsory membership of GPs, community and specialist nurses, and local health social services authorities in shared decisionmaking on service coordination.

The official evaluation of TPPs suggests that there are coordination/control trade-offs linked to organizational size. In bigger PC group practices, cooperation and shared decision-making are more difficult to obtain (due to higher decision costs and incentives for free-riding), but an equitable and cost-efficient allocation of clinical and financial risks across GPs and patient groups is easier to achieve due to bigger reference populations. In smaller practices, the higher prevalence of joint decision-making observed is linked to a greater reduction in referrals, but also might involve higher management and financial costs (Baxter et al. 2000). PC groups have also been studied since their creation (Audit Commission 1999; Wilkin et al. 2000). Evidence on the impact on delivery and outcomes is still lacking.

Experiments with network coordination mechanisms operating within public sector hierarchies were also launched in the Scandinavian countries, in which PC steers collective decision-making across care levels. The pioneering country was Denmark, where practising GPs started to be contracted by hospitals as part-time advisors and coordinators from the mid-1990s. The scheme, which spontaneously developed at the local level as a result of professional initiative, soon covered all Danish hospitals. At this stage, the national GP union negotiated salary complements to compensate GPs for their new tasks as coordinators; regional authorities, by agreement with the College of GPs, started to steer the process. In contrast with the British case, no market-based instruments were used to promote the scheme. By 1997, some 10 per cent of GPs worked as part-time coordinators, initially for hospitals, and latterly also for community purchasing boards led by local health authorities. There is some evidence that in the late 1990s other Scandinavian countries had started to introduce similar types of networks (Olesen et al. 1998).

Gatekeeping as a hierarchical coordination mechanism. Mechanisms through which hierarchical coordination power over other levels of care is delegated to GPs were introduced in European NHS-type health care systems starting in the 1960s. The most important example is the delegation of a gatekeeping function to GPs, establishing a monopoly over patient entry flows into specialist and community care. Until the advent of the 1990 pro-coordination reforms, administrative rules dominated the referral process, leaving little margin for choice of alternative providers. This is consistent with the fact that communication between GPs and other specialists was as weak in gatekeeping countries as in non-gatekeeping ones (e.g. Grundmeijer 1996; Vehvilainen et al. 1996; Gérvas et al. 2001). In spite of that, there is fairly robust evidence that gatekeeping curbs health expenditure, especially if operated by a resourceful PC sector (Gerdtham and Jönsson 2000).

Since the mid-1990s, some social health insurance (SHI) countries (e.g. France, Israel, Germany), and most countries of Central and Eastern Europe (CEE) launched reforms aimed at promoting gatekeeping. A recent study on the French experience shows that the planned introduction of the scheme was aborted due to the strong opposition of most professional associations, which ended up weakening the initial support of some PC associations (Polton 2004). The available evidence on the pioneering Dutch case points to additional problems in implementing the scheme under a SHI context characterized by patient choice of provider: the role of gatekeeper is apparently unpopular; and wealthier patients seem prepared to pay to go directly to a specialist (Kulu-Glasgow et al. 1998). Recent research findings concerning this theme are as follows. Countries where PC has gatekeeping functions include greater rationing of specialized care, mainly expressed through longer waiting lists; it is this second problem, and not the role as gatekeeper itself, that generates dissatisfaction (Grumbach et al. 1999). Finally, research in Israel emphasizes that attitudes towards gatekeeping vary across social classes and political parties, with the lower and middle classes in favour of it (Gross et al. 2000; Tabenkin and Gross 2000).

\subsection{Pro-coordination reforms expanding the service portfolio of PC provision}

Antecedents: The first wave of reforms. During the 1970s and 1980s, the service portfolio of PC in most European countries was being extended. New preventive and PC services were covered. In 
SHI countries, it developed as one response to market-like competition between independent GPs and medical specialists. In Beveridge countries with predominant public provision, it was affected by state regulation expanding task profiles at the PC level, and/or via hierarchical integration of several individual GP practices and other first-contact professionals within multidisciplinary PC teams. In the Beveridge countries where GPs are independent contractors, PC teams were formed by more network-like arrangements, like professional partnerships, long-term rent contracts, etc. GPs were free to decide whether to integrate or not and whom to integrate with, as well as to contract support staff autonomously. Accordingly, the constitution of multidisciplinary teams proceeded at a slow rhythm, and single-handed practices subsisted, co-existing with group ones (Gérvas et al. 1994; Starfield 1991; Boerma et al. 1997).

In SHI countries, expanded task-profiles via competition has led to duplication of services (Boerma et al. 1997). Available research concerning the impact of multidisciplinary groups in Beveridge countries also suggests that inter-professional collaboration is difficult to attain via hierarchical mechanisms only. Frequently the groups do not work together, with each professional working in a relatively isolated manner (Sergison et al. 1997). Without collaboration, task profiles expanded by decree are not easy to implement either. However, when there is shared decision-making and management of patients, results improve (Halliwell et al. 1999).

The 1990s pro-coordination reforms. During the 1990s, extension of services provided at this level took on a new rhythm in Western Europe. Preventive care (routine checks, health promotion clinics), community care (home, palliative and mental care), together with substitution of some hospital care (e.g. minor surgery, diagnostics, and rehabilitation) constituted the main objectives of reforms (Broadbent 1998; Florin 1999; Pritchard and Hughes 1995; Walzer et al. 1999; Halliwell et al. 1999). Three successive waves of reform were launched in Europe aimed at modifying the service portfolio of PC and other care levels, based respectively on market-based, network-like and hierarchical mechanisms, which in some countries overlapped in time.

In some Beveridge countries, and most notably in Great Britain, the unexpected outcome of marketbased incentives to expand PC tasks was again the spontaneous development by PC professionals of network cooperation with other PC colleagues and across the interface. As a result, a series of cooperative arrangements developed, closely linked to expanded PC task profiles, but also derived from the new powers of GPs as active coordinators of other care levels. Some examples of this type of experiment are as follows:

- outreach clinics that contract part-time specialists to attend consultations with the GPs in health centres

- integration of nurses specialized in community services (geriatrics, mental care, public health) into PC groups, but maintaining their contractual ties with their original level of care

- PC teams in charge of part-time provision and coordination of hospital accidents and emergencies departments

- GP cooperatives for the joint management and provision of out-of-hours care

- schemes of in-house referral to other GPs within group practices for specially complex or expensive cases

Evaluation of the results and characteristics of these experiences has begun. Most of the available literature concentrates on the relative cost-effectiveness of having PC deliver these services as compared to other providers (Bentur 2001; Bond et al. 2000; Somerset et al. 1999; Walker et al. 1999; Roland and Shapiro 1998; Williams et al. 1997; Dale et al. 1996; Scott 1996). PHC-based specialist care seems to be generally able to obtain similar health outcomes at less cost than other specialist consultants in the case of frequent conditions, which allows them to see enough patients annually to acquire the necessary skills directly. For less prevalent interventions, which rely more heavily on inter-professional collaboration, either hospitals or other specialist community providers (such as home care organizations or specialist nurses) apparently deliver more cost-effective care.

One problem is that existing assessments have not yet been in place long enough to permit evaluation of the long-term dynamics of substitution policies, which are likely to give a different picture than short-run investigations (due, for instance, to learning economies and slowly developing trust 
relationships between the actors involved). Moreover, they often do not include all the costs and benefits accruing to patients and GPs. In the few cases for which there is evidence, patient and GP satisfaction usually increased as a result of the assumption of new tasks by PC at the expense of other levels. This was due to the reduced travel time costs for patients, the improved opportunities for expanding knowledge and skills for GPs, and the enhanced continuity and comprehensiveness of care guaranteed by the new schemes.

In SHI countries, the expansion of tasks through pro-cooperation mechanism has been mainly stimulated by targeted economic incentives, in the form of public grants for spontaneously developed professional networks providing integrated care and disease management programmes for the chronically ill. The Netherlands pioneered "transmural" care reforms, which were launched in 1994. By 1999 there were 504 transmural networks in operation, involving almost all hospitals and home care providers in the country. GPs participated in 45 per cent of them and GP practices in 20 per cent (Van der Linden et al. 2001). France started similar reforms in 1996, but implementation was retarded by the slow collective decision-making process which led to the exclusion of the schemes of insurer-run managed care plans competing for public funds (Polton 2004). Germany followed in the late 1990s (Busse 2000).

\section{TOWARDS CONVERGENCE? DRIVERS AND BARRIERS OF PRO-COORDINATION REFORMS ACROSS EUROPE}

\subsection{Shared context and policy feedback: cooperation as a competitive strategy}

Few advances in inter-professional and inter-organizational collaboration were made prior to the 1990s. From then on, a series of transformations in the broader societal context, as well as some shared feedback effects, drove improvements in this field. Two types of policy feedback started to operate across European countries. Collaborative arrangements have indirectly (and mostly unexpectedly) resulted from broader reform measures aimed at fostering cost-containment and market competition. Improvements in PC financing, training and technology have significantly, although only slowly, reduced the structural obstacles to coordination.

As for the social context, a development overlooked in the previous literature is the impact of the increasing prevalence of chronic illnesses on the need for coordination between care services (since these patients are frequent users of all levels simultaneously). The resulting inter-organizational interdependencies pose critical problems for both market and hierarchical coordination. There are two main solutions to this problem (Scharpf 1993): (1) coordination power can be transferred to front-line professionals; and (2) organizational units can be expanded or merged, in order to internalize previous inter-unit interactions. These two strategies correspond well with the process of organizational restructuring in PC.

\subsection{Institutional and socio-political power legacies: the dynamics of hybridization and selective PD across Europe}

The common trend towards experimentation with pro-coordination reforms in Europe during the 1990s points to policy convergence across Europe. However, both the rhythm of reforms, and the fate of the different institutional and organizational mechanisms embodied within them, vary across groups of countries, suggesting differential selective PD patterns. Great Britain, Denmark, and to a lesser extent, the Netherlands, can be considered examples of best practice for the design of pro-cooperation reforms; and they have successfully implemented the attempted transfer of powers and tasks to PC. Comprehensive, strong inter-organizational networks emerged as a result. In SHI countries, additional public funds were made available to new, virtually integrated, hospital-centred networks. PC played a very minor role, and the initial attempts at expanding its powers and scale in France and Germany failed. In CEE and Southern Europe, the few pro-coordination experiments that were launched did not lead to institutional reform. Ex-communist countries, however, experimented with radical transformation of their health care systems towards the SHI model, including the privatization and disintegration of PC providers. Since the late 1990s they have started to incorporate some traditional 
Beveridge-type tools to strengthen PC. Serious financial difficulties, however, resulted in implementation gaps and a contraction of their health care systems.

Institutional legacies and PC organization. Next we examine the potential effects of the inherited institutional framework and socio-political structure (SPS) in explaining reform pathways across Europe. At the start of the 1990s, there were three main types of European health care systems, and four main models of PC organization. As for political institutions, the main actors with formal political power (FPP) in Beveridge or NHS-type countries (Nordic, Great Britain, and Southern Europe) were state authorities. This is also generally true for CEE countries during the early 1990s, when the transition to the SHI model was launched and implemented. From then on, political institutions in CEE countries started to move towards the neo-corporatist (network-like) schemes typical of SHI countries, based on joint decision-making by the state, insurers and professionals.

Organizationally, the map was as follows. In the countries which pioneered pro-cooperation reforms in Europe, most PC providers are independent partnerships under a long-term contract with the public sector, a type of network-like organizational arrangement (model 1, M1). They also share a relatively strong position of PC within system coordination (i.e. monopoly of first contact, multidisciplinary groups with expanded task profiles). In SHI countries, which developed weaker, hospital-centred coordination networks, PC professionals were also independent entrepreneurs, but most worked as individuals in competition with ambulatory specialists for first contact (model 2: M2). Publicly operated Beveridge countries (M3) share with M1 countries the strong coordination role of PC professionals; but these as state officials enjoy less autonomy (and other resources) than their private counterparts. The institutional position of PC in the CEE countries still retaining a Soviet model (M4) is considerably weaker than in Beveridge or Bismarck countries, with the partial exception of the exYugoslavian countries (Boerma et al. 2004).

Differences in political institutions can explain some of the different trajectories of reform across European countries. For instance: (1) in two of the three vanguard countries of Western Europe the state had monopoly FPP rights; and (2) a radical privatization of insurance and PC provision was rapidly implemented under the centralized rule of state authorities in CEE countries. They cannot explain (3) the pioneering role of The Netherlands, or (4) the fact that the 1990s pro-coordination reforms progressed more rapidly in SHI countries than in publicly operated Beveridge countries or CEE countries. Differences in PC organization and strength across Europe might explain the reform paths (1) and (3), but do not match well with developments (2) and (4). They do not explain either (5) why few advances in coordination across the interface were achieved before the 1990s in M1 countries.

Accounting for selective PD and hybridization: socio-political structures, redistributive policies and the centrality of the political process In section 2, we defined the SPS as the distribution of informal political power (IPP) resources (ownership, knowledge and social support) among the three major socio-political actors in health care (the state, insurers and professionals). For PC-based pro-coordination policies, the relative IPP of PC professionals versus other specialists can also be expected to play a critical role. We also developed two main hypotheses about the causal role of the SPS: (H1) that it is a major determinant of the political process, and, therefore, of the likelihood of policy change; and (H2) that changes in the SPS result from the interaction between wide societal pressures and specific policy feedback processes (with redistributive policies expected to have a prominent role). Both hypotheses apparently fit the available evidence well.

(H1) In the three vanguard M1 countries as well as in SHI M2 countries PC professionals are private entrepreneurs; they therefore share ownership-based IPP with the state (who often own most hospitals). This also increases their professional status vis-à-vis their salaried hospital colleagues. However, in all SHI countries the monopsonic power of the state in financing is shared with insurance companies and ambulatory care is largely privately owned and operated; in addition, and with the exception of the Netherlands, PC shares its market power with ambulatory specialists, who control more than 50 per cent of the first contact care market (Boerma et al. 1997). This in turn points to lower patient support for PC professionals vis-à-vis specialists in M2 than in M1 countries. In M1 countries, relatively autonomous PC group practices provide more opportunities to expand the knowledge-based IPP, and to assume new functions. In contrast, in most M3 and M4 countries, PC 
doctors do not enjoy ownership-based IPP; and as in M2 countries, they are frequently skipped by the upper social classes (private specialist care), and consequently enjoy less market power and support from them. CEE M4 countries mainly differ from WE M3 countries in that the support for the private sector also extended during the 1990s to the middle and lower classes, following the financial and political breakdown of the ex-Soviet Union.

These differences in the SPS structure across countries, and its effects on the political process, go a great way to explain the differential reform patterns numbered as (1)-(5) in the subsection above. They imply that PC professionals are powerful lay actors within the political process in M1 countries; a weaker presence in SHI countries, where insurers and ambulatory specialists are their direct competitors; and a nearly irrelevant role in M3 and M4 countries. In fact, there is evidence that strong PC associations, the natural coalition parties of state authorities in PC-based pro-coordination reforms, helped design and ended up supporting the reform schemes both in Denmark and Great Britain (Olesen et al. 1998; Whynes et al. 1999), thereby facilitating policy change and granting implementation. There is also evidence that the fierce informal opposition of powerful professional (specialist-dominated) associations divided PC professionals, initially favourable, and ended up blocking PC-based pro-coordination reforms in France (Polton 2004).

(H2) The predominant role of the SPS as a determinant of the likelihood of policy change does not however imply that the differential patterns of selective PD are immutable. The best-performing countries in Europe in terms of pro-coordination policies are also the ones which have effected a major redistribution of financial and human resources towards and within the PC level (Halliwell et al. 1999; Bloor et al. 2000; J enkins-Clarke et al. 1997). This helps explain a critical fact so far unaccounted for, namely the final support of PC professionals and citizens after their initial frontal opposition in most countries. Generally speaking, state authorities in SHI played a more hands-off, reactive role by comparison with the pro-active, targeted interventions in the pioneering Beveridge countries. Redistributive policies (e.g. improvements in training) usually take more time to obtain the expected results than regulatory policies. Recent reform experiences in CEE countries, carefully tailored to effect a shift of resources towards PC, also suggest that other redistributive policies (like financial or manpower transfers) can attain more rapid effects (McKee 2004).

\section{SUMMARY AND POLICY IMPLICATIONS}

During the 1990s, a series of parallel pro-coordination reforms involving a broader organizational restructuring in health care were launched and implemented across Europe. New sophisticated virtual integration strategies were tailor-made to promote cooperation and redistribute functions and resources across the interface. Virtual integration allows for simultaneous enjoyment of the advantages of autonomy and of organizational integration. The countries in which PC was strong, and closer to the network model prior to the 1990s (mainly Great Britain, Denmark and the Netherlands), are examples of best practice also in the latest generation of PC-based pro-cooperation policies and supporting mechanisms. In these countries, powerful PC associations ended up supporting state-induced reforms, facilitating policy change. While there is inconclusive evidence on the impact of these changes, existing research points to substantial cost-effectiveness and satisfaction improvements. In European SHI countries, PC-based pro-coordination experiments have been blocked by powerful professional (specialist-dominated) groups and insurers' associations, faced with relatively weak PC associations groups and hesitant state authorities; and more limited and weaker professional virtual networks resulted therefore from more acute contextual pressures. Elsewhere there was only limited experimentation with pro-cooperation reforms by health care professionals, which were often not given the necessary state support.

Cooperative networks hold considerable promise of achieving system coordination in health care, but they are not self-sustaining, and require demanding supporting conditions to be effective. Some market mechanisms, like decentralization of purchasing power to PC groups, seem to induce cooperation. Others, like competition, can inhibit it. The public sector can play an important role in removing the obstacles for networks to effect cost-efficient system coordination, by regulating network participants, financial mechanisms, and decision-making rules; and by providing supporting services (information and research, juridical and financial advice, etc.). More generally, inter- 
organizational coordination involves tasks not previously performed in health care systems.

Consequently, in spite of its potential long-term cost-reducing effect, an initial increase in resources is needed. In fact a basic policy implication of our research findings is that the transfers of powers and tasks should be tightly coupled with parallel shifts in accountability and resources to be successful.

\section{ACKNOWLEDGEMENT}

Based on the preliminary work done for the book "Primary care in the driver's seat? Organizational reform of primary care in Europe", jointly funded by the European Observatory on Health Care Systems and the Nuffield Trust. The authors are also grateful to the EU Network COST A15, which supported the group discussion of previous versions of the paper.

\section{TABLES AND FIGURES}

\section{Figure I}

\section{Determinants and dynamics of policy change}

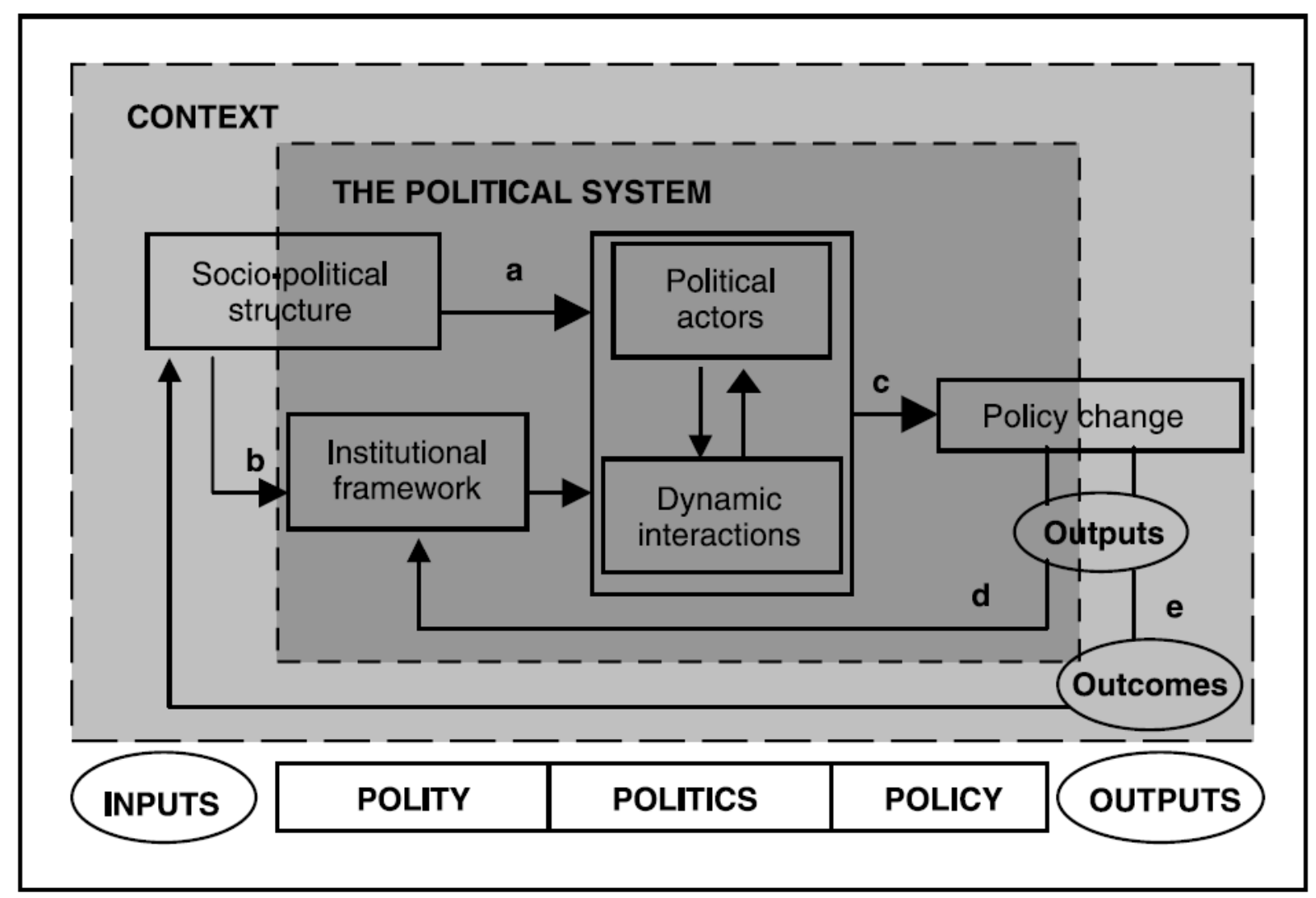

\section{REFERENCES}

Audit Commission (1999), PCGs: An Early View of Primary Care Groups in England, London: Stationery Office.

Bartlett, W. (1996), The regulation of general practice in the UK, International Journal of Health Planning and Management, 11: 3-18.

Baxter, K., Bachmann, M. and Bevan, G. (2000), PC groups: trade-offs in managing budgets and risk, Public Money and Management, 20, 1: 53-61.

Bentur, N. (2001), Hospital at home: what is its place in the health system? Health Policy, 55: 71-9. 
Bloor, K., Maynard, A. and Street, A. (1992), How Much Is a Doctor Worth? Discussion paper no. 98, Centre for Health Economics, University of York

Bloor, K., Maynard, A. and Street, A. (2000), The cornerstone of Labour's New NHS: Reforming PC. In P. Smith (ed.), Reforming Markets in Health Care, Buckingham: Open University Press.

Boerma, W., Dubois, C. A., Rico, A. and Saltman, R. (2004), Mapping PC organization in Europe. In R. Saltman, A. Rico and W. Boerma (eds), Primary Care in the Driving Seat? Organizational Reforms in European Health Care, Buckingham: Open University Press (in preparation).

Boerma, W., Van der Zee, J. and Fleming, D. M. (1997), Service profiles of GPs in Europe, British Journal of General Practice, 47: 481-6.

Bond, M., Bowling, A., Abery, A., McClay, M. and Dickinson, E. (2000), Evaluation of outreach clinics held by specialists in general practice in England, British Medical Journal, 54: 149-56.

Broadbent, J. (1998), Practice nurses and the effects of the new GP contract in the British NHS: the advent of a professional project? Social Science and Medicine, 47: 497-506.

Buckley, G. (1999), Revalidation is the answer to one question-but many more remain, British Medical Journal, 319: 1145-6.

Busse, R. (2000), Health Care Systems in Transition: Germany, Copenhagen: European Observatory on Health Care Systems.

Callaghan, G., Exworthy, M., Hudson, B. and Peckham, S. (2000), Prospects for collaboration in PC: relationships between social services and the PCGs, Journal of Inter-professional Care, 14: 19-26.

Dale, J., Lang, H., Roberts, J., Green, J. and Glucksman, E. (1996), Cost effectiveness of treating PC patients in A \& E departments, British Medical Journal, 312: 1340-4.

Florin, D. (1999), Scientific uncertainty and the role of expert advice: the case of health checks for coronary heart disease prevention by GPs in the UK, Social Science and Medicine, 49: 1269-83.

Gerdtham, U.-G. and Jönsson, B. (2000), International comparisons of health expenditure: theory, data and econometric analysis. In A. J. Culyer and J. P. Newhouse (eds), Handbook of Health Economics, vol 1, Amsterdam: Elsevier.

Gérvas, J., Palomo, L., Pastor-Sánchez, R., Pérez-Fernández, M. and Rubio, C. (2001), Problemas acuciantes en atención primaria [Pressing problems in PC], Atención Primaria, 28, 7: 472-7.

Gérvas, J., Pérez-Fernández, M. and Starfield, B. H. (1994), PC, financing and gate-keeping in western Europe, Family Practice, 11: 307-17.

Goddard, M. and Mannion, R. (1998), From competition to cooperation: new economic relationships in the National Health Service, Health Economics, 7: 105-19.

Goddard, M., Mannion, R. and Smith, P. (2000), Enhancing performance in health care: a theoretical perspective on agency and the role of information, Health Economics, 9: 95-107.

Goodwin, N. (1998), GP fundholding. In J. Le Grand, N. Mays and J. Mulligan (eds), Learning from the NHS Internal Market: a Review of the Evidence, London: King's Fund.

Grielen, S. J., Boerma, W. G. W. and Groenewegen, P. (2000), Unity or diversity? Task profiles of GPs in Central and Eastern Europe, European Journal of Public Health, 10: 249-54.

Gross, R., Tabenkin, H. and Bramli-Greenberg, S. (2000), Who needs a gatekeeper? Patients' views of the role of the PC physician, Family Practice, 17, 3: 222-9.

Grumbach, K., Selby, J., Damberg, C., Bindman, A., Quesenberry, C., Truman, A. and Uratsu, C. (1999), Resolving the gatekeeper conundrum: what patients value in PC and referral to specialists, Journal of the American Medical Association, 282, 3: 261-6.

Grundmeijer, H. (1996), GP and specialist: why do they communicate so badly? European Journal of General Practice, 2: 53-5.

Halliwell, S., Sibbald, B. and Rose, S. (1999), A Bibliography of Skill-mix in Primary Care: The Sequel, NCRPC working paper, University of Manchester.

Harrison, M. and Calltorp, J. (2000), The reorientation of market-oriented reforms in Swedish health care, Health Policy, 50: 219-40.

Harrison, S. (2001), Structural interests in health care: reforming the UK medical profession. In M. Bovens, P. t'Hart and G. Peters (eds), Success and Failure in Government. A Comparative Analysis, Aldershot: Edward Elgar.

Hughes Tuohy, C. (1999), Dynamics of a changing health sphere: the United States, Britain, and Canada, Health Affairs, 18, 3: 114-34.

Hunter, D. (2000), Disease management: has it a future? British Medical Journal, 320: 530.

Jenkins-Clarke, S., Carr-Hill, R., Dixon, P. and Pringle, M. (1997), Skill Mix in Primary Care-A Study of the Interface between the GP and Other Members of the Primary Health Care Team, Occasional paper no. 29, York: Centre for Health Economics.

Kulu-Glasgow, I., Delnoij, D. and de Bakker, D. (1998), Self-referral in a gate-keeping system: patients' reasons for skipping the GP, Health Policy, 45: 221-38. 
Landau, J. (2001), Organizing GPs into group practices in Italy. Paper presented to the 2001 Conference of the EHMA, Granada: 24-5 June.

McKee, M., Maclehose, L. and Rico, A. (2004), Health care needs and reform trends. In M. McKee, L. Maclehose and R. Busse (eds), Health Care Reforms in Pre-accession Countries, Buckingham: Open University Press (in press).

Mannion, R. and Smith, P. (1997), Trust and reputation in community care: theory and evidence. In P. Anand and A. McGuire (eds), Changes in Health Care: Reflection on the NHS Internal Market, London: Macmillan.

Mays, N., Mulligan, J. and Goodwin, N. (2000), The British quasi-market in health care: a balance sheet of the evidence, Journal of Health Services and Research Policy, 5: 49-58.

Mays, P. G., Halverson, P. K. and Kaluzny, A. D. (1998), Collaboration to improve community health, Journal on Quality Improvement, 24: 518-40.

Olesen, F., Jensen, P. B., Grinsted, P. and Henriksen, J. S. (1998), GPs as advisers and coordinators in hospitals, Quality in Health Care, 7: 42-7.

Polton, D. (2004), The French experience. Unpublished case study prepared for R. Saltman, A. Rico and W. Boerma, Primary Care in the Driving Seat? Organizational Reforms in European Health Care, Buckingham: Open University Press (in preparation).

Pritchard, P. and Hughes, J. (1995), Shared Care: the Future Imperative?

London: Royal Society of Medicine Press.

Rico, A. and Costa, J. (2004), Power rather than path? The dynamics of health policy under health care federalism, Journal of Health Politics, Policy and Law (forthcoming).

Ring, S. P. and Van de Ven, A. H. (1992), Structuring cooperative relationships between organizations, Strategic Management Journal, 13: 483-98.

Roberts, E. and Mays, N. (1998), Can PC and community-based models of emergency care substitute for the hospital A \& E department? Health Policy, 44: 191-214.

Roland, E. M. and Shapiro, J. (1998), Specialist outreach clinics in general practice, British Medical Journal, 316: 1028.

Saffran, D. G., Rogers, W. H., Tarlov, A. R., Inui, T., Taira, D. A., Montgomery, J. E., Ware, J. E. and Slavin, C. P. (2000), Organizational and financial characteristics of health plans. Are they related to PC performance? Archives of Family Medicine, 160: 69-76.

Salisbury, C., Trivella, M. and Bruster, S. (2000), Demand for and supply of out of hours care from GPs in England and Scotland, British Medical Journal, 320: 618-21.

Scharpf, F. (1993), Coordination in hierarchies and networks. In F. Scharpf (ed.), Games in Hierarchies and Networks, Frankfurt: Campus Verlag.

Scharpf, F. (1988), The joint-decision making trap, Public Policy and Administration, 66: 239-78.

Scott, A. (1996), Primary or secondary care? What can economics contribute to evaluation at the interface? Journal of Public Health Medicine, 18: 19-26.

Sergison, M., Sibbald, B. and Rose, S. (1997), Skill Mix in PC: A Bibliography, NCRPC working paper, Manchester: University of Manchester.

Sheaff, R. (1999), The development of English primary care group governance: a scenario analysis, International Journal of Health Planning and Management, 14: 257-68.

Somerset, M., Faulkner, A. and Shaw, A. (1999), Obstacles on the path to a primary-care led National Health Service: complexities of outpatient care, Social Science and Medicine, 48: 213-25.

Starfield, B. (1991), PC and health. A cross-national comparison, Journal of the American Medical Association, 266: 2268-71.

Tabenkin, H. and Gross, R. (2000), The role of the PC physician in the Israeli health care system as a gatekeeper-the viewpoint of health care policy makers, Health Policy, 52: 73-85.

Van der Linden, B., Spreeuwenberg, C. and Schrijvers, A. J. (2001), Integration of care in the Netherlands: the development of transmural care since 1994, Health Policy, 55: 111-20.

Vehvilainen, A. T., Kumpusalo, A. and Takala, J. K. (1996), Feedback information from specialists to general practitioners in Finland, European Journal of General Practice, 2: 55-7.

Walker, Z., McKinnon, M. and Townsend, J. (1999), Shared care for high-dependency patients: a review, Health Services Management Centre, 12: 205-11.

Webb, A. (1991), Coordination: a problem in public sector management, Policy and Politics, 19: 22941.

Whynes, D. K., Ennew, C. T. and Feighan, T. (1999), Entrepreneurial attitudes of primary health care physicians in the United Kingdom, Journal of Economic Behaviour and Organization, 38: 331-47.

Wilkin, D., Gillam, S. and Leese, B. (2000), The National Tracker Survey of PC Groups and Trusts. Progress and challenges, 1999/2000, London: Kings Fund. 
A.Rico; R.B. Saltman; W.G.W. Boerma

Organizational restructuring in European health systems: the role of primary care.

Social Policy \& Administration: vol. 37, 2003, nr. 6, p. 592-608.

Williams, G., Flynn, R. and Pickard, S. (1997), Paradoxes of GP fundholding: contracting for community health services in the British NHS, Social Science and Medicine, 45: 1669-78. 